\title{
Toll-Like Receptor 10-1-6 Gene Cluster Polymorphisms Are Not Associated With Benign Prostatic Hyperplasia in Korean Population
}

\author{
Su Kang Kim, Young Ock Kim¹, Byung-Cheol Lee², Koo Han Yoo 3 , Joo-Ho Chung \\ Department of Pharmacology, Kohwang Medical Research Institute, Kyung Hee University School of Medicine, Seoul; \\ ${ }^{1}$ Development of Ginseng and Medical Plants Research Institute, Rural Administration, Eumseong; \\ ${ }^{2}$ Department of Internal Medicine, Kyung Hee University College of Oriental Medicine, Seoul; \\ ${ }^{3}$ Department of Urology, Kyung Hee University School of Medicine, Seoul, Korea
}

\begin{abstract}
Purpose: Inflammation and infection have been associated with the pathogenesis of benign prostatic hyperplasia (BPH). Toll-like receptors (TLRs) play key roles in the innate immune system and initiate the inflammatory response to foreign pathogens. We investigated the relationship between TLR10-1-6 gene cluster polymorphisms and $\mathrm{BPH}$.

Methods: We genotyped four promoter single nucleotide polymorphisms (SNPs) (TLR10, rs10004195; TLR1, rs5743557; and TLR6, rs 1039560 and rs1039559) by directly sequencing (233 BPH patients and 214 control subjects). SNPStats and Haploview version 4.02 were used to analyze the data. Multiple logistic regression models (log-additive, dominant, and recessive) were performed to determine odds ratios (ORs), 95\% confidence intervals (CIs), and P-values.

Results: The genotype and allele frequencies of each SNP was not different between the BPH and control groups $(\mathrm{P}>0.05)$. Haplotype analysis showed no association between the haplotype in the linkage disequilibrium (LD) block and $\mathrm{BPH}(\mathrm{P}>0.05)$, although the LD block was constructed.

Conclusions: These results indicate that the TLR10-1-6 gene cluster may be not associated with the development of BPH in the Korean population.
\end{abstract}

Keywords: Prostatic hyperplasia; Single nucleotide polymorphism; Toll-like receptors

\section{INTRODUCTION}

Benign prostatic hyperplasia (BPH) is a common urological condition caused by the nonmalignant proliferation of epithelial and stromal cells in the prostate gland during the aging process in men. This condition occurs most often in men over the age of 60 . The risk factors of $\mathrm{BPH}$ are thought to be age, family history, and heart disease. However, the exact etiology of $\mathrm{BPH}$ is still unknown. From recent genetic studies, scientists have suggested that specific gene polymorphisms are associated with the development of $\mathrm{BPH}$.

Toll-like receptors (TLRs) play important roles in the recog- nition of components of pathogens and subsequent activation of innate immunity. TLRs are involved in the regulation of inflammatory reactions and activation of adaptive immune responses to remove harmful pathogens [1,2].

In mammals, the human TLR family includes the TLR3, TLR4, TLR5, TLR2, and TLR9 subfamilies. The TLR2 subfamily is composed of TLR2 and TLR10-1-6 clusters [3]. The amino acid sequence of human TLR6 is most similar to that of human TLR1, as they share 69\% sequence identity [4]. TLR6 is expressed predominantly in the spleen, thymus, lung, and ovary. TLR1 is expressed in peripheral blood lymphocytes, epithelial cells, and endothelial cells, and TLR10 is highly expressed in the spleen
Corresponding author: Joo-Ho Chung

Department of Pharmacology, Kohwang Medical Research Institute, Kyung Hee

University School of Medicine, 26 Kyungheedae-ro, Dongdaemun-gu,

Seoul 130-701, Korea

Tel: +82-2-921-0281 / Fax: +82-2-968-0560 / E-mail: jhchung@khu.ac.kr

Submitted: January 6, 2014 / Accepted after revision: March 6, 2014
This is an Open Access article distributed under the terms of the Creative Commons Attribution Non-Commercial License (http://creativecommons.org/licenses/by-nc/3.0/) which permits unrestricted non-commercial use, distribution, and reproduction in any medium, provided the original work is properly cited. 
and B-cells $[5,6]$. Several studies have reported associations between TLRs and various diseases, such as papillary thyroid cancer [2], hepatitis $\mathrm{C}$ virus infection [7], and myocardial infarction [8].

Chronic inflammation mediated by cytokines and inflammatory cells has been investigated in BPH [9]. TLR-dependent signaling pathways lead to the activation of immune responses and play an important role in host defense against microbes. Both prostate epithelial and stromal cells express TLR2, TLR3, and TLR4 in response to bacterial antigens and increased the expression of interleukin (IL) 1 and IL-15 [10,11] once stimulated. Moreover, the association between TLR and prostate carcinogenesis has been reported. TLR4 and TLR10-1-6 in prostate cells may possibly synergize with innate immune cells, contributing to an eventual inflammatory process, including prostate cancer $[12,13]$.

The aim of present study was to investigate whether TLR6-110 single nucleotide polymorphisms (SNPs) are associated with the development of $\mathrm{BPH}$ in a Korean population.

\section{MATERIALS AND METHODS}

\section{Study Subjects}

Two hundred and thirty three BPH patients who visited the Kyung Hee University Medical Center between January 2002 and December 2006 for lower urinary tract symptoms were enrolled in this study. The presentation of clinical symptoms was checked against the International Prostate Symptom Score (IPSS), and the prostate volume of all patients was assessed using transrectal ultrasonography (TRUS). Patients with serum prostatespecific antigen (PSA) levels greater than $4 \mathrm{ng} / \mathrm{mL}$ underwent a TRUS-guided prostate biopsy to rule out prostate cancer.

A total of 214 age-matched, healthy control subjects were recruited from patients visiting the hospital for routine checkups. All control subjects were screened for normal PSA levels and the absence of symptoms that suggest BPH or malignancy. Control subjects and $\mathrm{BPH}$ patients with prostate cancer, neurogenic bladders, urethral strictures, acute/chronic prostatitis, urinary tract infections, uncontrolled diabetes mellitus, previous pelvic surgery, or hypertension were excluded from this study.

We divided BPH subjects into subgroups based on prostate volume ( $<30 \mathrm{~g}$ and $\geq 30 \mathrm{~g}$ ) and PSA levels $(<1.5 \mathrm{ng} / \mathrm{mL}$ and $\geq 1.5 \mathrm{ng} / \mathrm{mL}$ ) and analyzed their relationship with the TLR 101-6 gene cluster. All patients provided informed consent for the use of their samples and clinical data. This study was approved in 2009 by the institutional review board at Kyung Hee University Medical Center.

\section{SNP Selection and Genotyping}

We selected four TLR10-1-6 gene cluster SNPs (TLR10, rs 10004195 [-89T/A, promoter]; TLR1, rs5743557 [-459C/T, promoter]; and TLR6, rs1039560 [-344A/G, promoter] and rs1039559 [-436T/C, promoter]) with greater than 0.3 heterozygosity among SNPs located in the promoter region for analysis (http://www.ncbi.nlm.nih.gov/SNP) [2]. Genotypes were determined by direct sequencing. Before sequencing, Polymerase chain reaction (PCR) was performed. Genomic DNA was amplified using the following primers: TLR10, rs1004195 (sense, 5plified using tTTTGCGGGA-3'; antisense, 5'-ACCCCACGGCTTGCACTCTCTC-3'; a 395-bp product); TLR1, rs5743557 (sense, 5pl CAGTGGAAAAAAATTCAGCACC-3ied using tTTTGCGGGA-3'; antisense, 5'-ACCCCACGG-bp product); and TLR6, rs1039560 and rs1039559 (sense, 5tTTTGCGGGA-3'; anGACCTGT-3'; antisense, 5'-TGTTGGATCACTTTCTCAATGC-3 (sense,-bp product). PCR was performed for 38 cycles at $94^{\circ} \mathrm{C}$ for 30 seconds, $58^{\circ} \mathrm{C}$ for 30 seconds, $72^{\circ} \mathrm{C}$ for 1 minute, and $1 \mathrm{cycle}$ at $72^{\circ} \mathrm{C}$ for 7 minutes to terminate the reaction. The PCR products were identified using 1.5\% agarose gel electrophoresis and ethidium bromide staining. The genotype of each gene was sequenced using an ABI Prism 377 automatic sequencer (PE Applied Biosystems, Foster City, CA, USA). Sequence data were analyzed using the SeqManII software v2.3 (DNASTAR Inc., Madison, WI, USA).

\section{Statistical Analysis}

We analyzed the genetic data to find associations with $\mathrm{BPH}$. SNPStats (http://bioinfo.iconcologia.net/index.php) was used to perform the analysis. Multiple logistic regression models (logadditive, dominant, and recessive models) were used to calculate odds ratios (ORs), 95\% confidence intervals (CIs), and corresponding P-values controlling for age as a covariable. A linkage disequilibrium (LD) block of TLR10-1-6 gene cluster polymorphisms was tested using Haploview ver. 4.02 (Broad Institute, Cambridge, MA, USA) [14].

\section{RESULTS}

The clinical characteristics of the $233 \mathrm{BPH}$ patients are shown in Table 1 . There was no statistically significant difference in mean age between the BPH (66.75 \pm 8.22 years) and control (67.45 \pm 9.67 
years) groups $(\mathrm{P}=0.410)$. The mean of the total prostate volume for the BPH group was $39.14 \pm 21.42 \mathrm{~mL}$ and the mean of total PSA levels was $3.89 \pm 3.55 \mathrm{ng} / \mathrm{mL}$.

We genotyped $233 \mathrm{BPH}$ patients and 214 control subjects to investigate whether four promoter SNPs of the TLR10-1-6 gene

Table 1. Characteristics of benign prostatic hyperplasia patients $(\mathrm{n}=233)$

\begin{tabular}{lc}
\hline Characteristic & Value \\
\hline Age $(\mathrm{yr})$ & $66.75 \pm 8.22$ \\
IPSS & $17.09 \pm 7.85$ \\
Quality of life & $3.61 \pm 1.34$ \\
Prostate volume $(\mathrm{mL})$ & \\
Total & $39.14 \pm 21.42$ \\
Transition zone & $18.96 \pm 15.01$ \\
Prostate-specific antigen $(\mathrm{ng} / \mathrm{mL})$ & \\
Total & $3.89 \pm 3.55$ \\
Free & $0.99 \pm 0.87$ \\
Uroflowmetry & \\
Qmax (mL/sec) & $12.97 \pm 5.81$ \\
Qavg $(\mathrm{mL} / \mathrm{sec})$ & $7.44 \pm 3.58$ \\
VV (mL) & $218.00 \pm 18.00$ \\
PVR (mL) & $64.88 \pm 53.94$ \\
\hline
\end{tabular}

Values are presented as mean \pm standard deviation.

IPSS, international prostate symptom score; Qmax, maximum flow rate; Qavg, average flow rate; VV, voided volume; PVR, postvoid residual volume. cluster were associated with BPH. Tables 2 and 3 show the genotype and allele distributions of four SNPs in both the BPH and control groups. The genotype distributions of the four SNPs were in Hardy-Weinberg equilibrium in the control group (TLR10, rs10004195, $\mathrm{P}=0.50$; TLR1, rs5743557, $\mathrm{P}=1.00$; and TLR6, rs1039560, $\mathrm{P}=0.46$ and $\mathrm{rs1039559,} \mathrm{P}=0.46)$. The genotype distributions of the SNPs in the BPH group were similar to those of the control group. These differences were not statistically significant (TLR10, rs10004195; OR, 0.90; 95\% CI, 0.68-1.20; and $\mathrm{P}=0.47$ in the log-additive model [T/T vs. T/A vs. $\mathrm{A} / \mathrm{A}] ;$ TLR1, rs5743557; OR, 0.79; 95\% CI, 0.59-1.07; and $\mathrm{P}=0.12$ in the logadditive model [C/C vs. C/T vs. T/T]; and TLR6, rs1039560 rs1039559; OR, 1.28; 95\% CI, 0.91-1.81; and $\mathrm{P}=0.16$ in the logadditive model [A/A vs. A/G vs. G/G] and OR, 1.28; 95\% CI, $0.91-1.81$; and $\mathrm{P}=0.16$ in the $\log$-additive model $[\mathrm{T} / \mathrm{T}$ vs. $\mathrm{T} / \mathrm{C}$ vs. $\mathrm{C} / \mathrm{C}$, respectively). In the allele distribution analysis, there were significant differences between the allele distributions in the $\mathrm{BPH}$ and control groups (Table 3$)(\mathrm{P}>0.05)$.

The four SNPs in TLR10-1-6 were analyzed for LD and haplotypes using Haploview 4.02. The LD block was composed of rs1039560 and rs1039559 (Fig. 1) and strongly constructed $\left(\mathrm{D}^{\prime}=1.0\right.$, and $\left.r^{2}=1.0\right)$. The haplotypes in the LD block were AT (frequency, 0.745) and GC (frequency, 0.255) in Table 4. The haplotypes consisted of rs1039560 and rs1039559 and revealed no significance (AT haplotype: chi-square $=1.208, \mathrm{P}=0.27$; and GC haplotype: chi-square $=1.208, \mathrm{P}=0.27)$.

Based on the prostate volume ( $<30 \mathrm{~g}$ and $\geq 30 \mathrm{~g})$ and PSA

Table 2. Genotype frequencies of TLR10-1-6 gene cluster polymorphisms in BPH patients and controls

\begin{tabular}{|c|c|c|c|c|c|c|c|}
\hline Gene symbol & SNP (locus) & Genotype & BPH, n (\%) & Control, n (\%) & Model & OR (95\% CI) & P-value \\
\hline \multirow[t]{3}{*}{ TLR10 } & rs10004195 & $\mathrm{T} / \mathrm{T}$ & $54(25.2)$ & $65(27.9)$ & Log-additive & $0.90(0.68-1.20)$ & 0.47 \\
\hline & promoter & $\mathrm{T} / \mathrm{A}$ & $102(47.7)$ & $110(47.2)$ & Dominant & $0.79(0.49-1.26)$ & 0.32 \\
\hline & & $\mathrm{A} / \mathrm{A}$ & $58(27.1)$ & $58(24.9)$ & Recessive & $0.96(0.60-1.54)$ & 0.86 \\
\hline \multirow[t]{3}{*}{$T L R 1$} & rs5743557 & $\mathrm{C} / \mathrm{C}$ & $54(25.2)$ & $71(30.5)$ & Log-additive & $0.79(0.59-1.07)$ & 0.12 \\
\hline & promoter & $\mathrm{C} / \mathrm{T}$ & $107(50.0)$ & $115(49.4)$ & Dominant & $0.68(0.42-1.08)$ & 0.10 \\
\hline & & $\mathrm{T} / \mathrm{T}$ & $53(24.8)$ & $47(20.2)$ & Recessive & $0.80(0.49-1.32)$ & 0.39 \\
\hline \multirow[t]{3}{*}{ TLR6 } & rs1039560 & $\mathrm{A} / \mathrm{A}$ & $126(58.9)$ & $121(51.9)$ & Log-additive & $1.28(0.91-1.81)$ & 0.16 \\
\hline & promoter & $\mathrm{A} / \mathrm{G}$ & $74(34.6)$ & $98(42.1)$ & Dominant & $1.44(0.95-2.19)$ & 0.08 \\
\hline & & $\mathrm{G} / \mathrm{G}$ & $14(6.5)$ & $14(6.0)$ & Recessive & $1.01(0.42-2.40)$ & 0.98 \\
\hline \multirow[t]{3}{*}{ TLR6 } & rs1039559 & $\mathrm{T} / \mathrm{T}$ & $126(58.9)$ & $121(51.9)$ & Log-additive & $1.28(0.91-1.81)$ & 0.16 \\
\hline & promoter & $\mathrm{T} / \mathrm{C}$ & $74(34.6)$ & $98(42.1)$ & Dominant & $1.44(0.95-2.19)$ & 0.08 \\
\hline & & $\mathrm{C} / \mathrm{C}$ & $14(6.5)$ & $14(6.0)$ & Recessive & $1.01(0.42-2.40)$ & 0.98 \\
\hline
\end{tabular}

P-values were derived from logistic regression analyses with the log-additive, dominant, and recessive models.

TLR, toll-like receptor; BPH, benign prostatic hyperplasia; SNP, single nucleotide polymorphism; OR, odds ratio; CI, confidence interval. 
Table 3. Allele frequencies of TLR10-1-6 gene cluster polymorphisms in BPH patients and controls

\begin{tabular}{|c|c|c|c|c|c|c|}
\hline Gene symbol & SNP (locus) & Allele & Control, n (\%) & $\mathrm{BPH}, \mathrm{n}(\%)$ & OR (95\% CI) & P-value \\
\hline \multirow[t]{2}{*}{ TLR10 } & rs10004195 & $\mathrm{T}$ & $210(49.1)$ & $240(51.5)$ & 1 & \\
\hline & & A & $218(50.9)$ & $226(48.5)$ & $0.91(0.70-1.185)$ & 0.47 \\
\hline \multirow[t]{2}{*}{ TLR1 } & rs5743557 & $\mathrm{C}$ & $215(50.2)$ & $257(55.2)$ & 1 & \\
\hline & & $\mathrm{T}$ & $213(49.8)$ & $209(44.8)$ & $0.82(0.63-1.07)$ & 0.14 \\
\hline \multirow[t]{2}{*}{ TLR6 } & rs1039560 & A & $326(76.2)$ & $340(73.0)$ & 1 & \\
\hline & & G & $102(23.8)$ & $126(27.0)$ & $1.18(0.88-1.60)$ & 0.27 \\
\hline \multirow[t]{2}{*}{ TLR6 } & rs1039559 & $\mathrm{T}$ & $326(76.2)$ & $340(73.0)$ & 1 & \\
\hline & & $\mathrm{C}$ & $102(23.8)$ & $126(27.0)$ & $1.18(0.88-1.60)$ & 0.27 \\
\hline
\end{tabular}

TLR, toll-like receptor; SNP, single nucleotide polymorphism; BPH, benign prostatic hyperplasia; OR, odds ratio; CI, confidence interval.

Table 4. Haplotype analysis for association between the TLR10-1-6 gene cluster polymorphisms and BPH

\begin{tabular}{|c|c|c|c|c|c|c|c|}
\hline \multirow{2}{*}{ Haplotype } & \multirow{2}{*}{ Frequency } & \multicolumn{2}{|c|}{ Control } & \multicolumn{2}{|c|}{$\mathrm{BPH}$} & \multirow{2}{*}{ Chi-square } & \multirow{2}{*}{ P-value } \\
\hline & & + & - & + & - & & \\
\hline AT & 0.745 & 326 & 102 & 340 & 126 & 1.208 & 0.27 \\
\hline GC & 0.255 & 102 & 326 & 126 & 340 & 1.208 & 0.27 \\
\hline
\end{tabular}

(+), ratio a specific haplotype of case or control; (-), ratio not a specific haplotype of case or control. Haplotype consists of rs1039560 and rs1039559. $\mathrm{TLR}$, toll-like receptor; $\mathrm{BPH}$, benign prostatic hyperplasia.

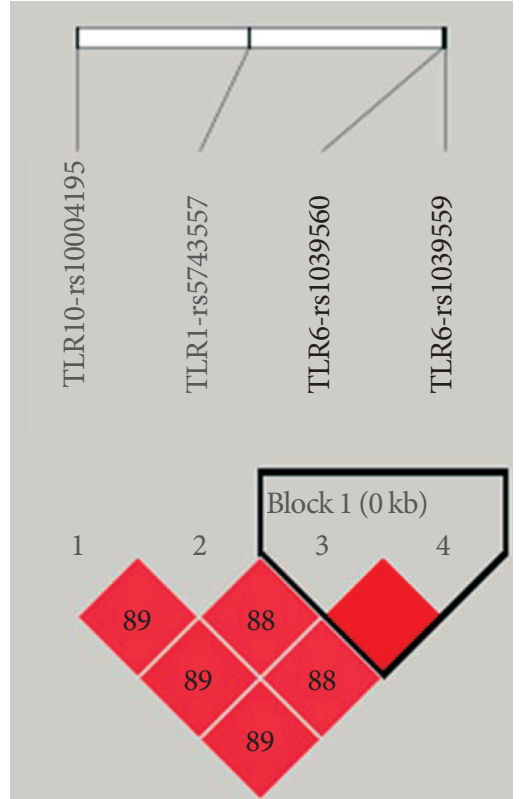

Fig. 1. Linkage disequilibrium block consists of rs1039560 and rs1039559. TLR, toll-like receptor.

levels ( $<1.5 \mathrm{ng} / \mathrm{mL}$ and $\mathrm{g} 1.5 \mathrm{ng} / \mathrm{mL}$ ) in the BPH subgroup, we did not find any differences in TLR10-1-6 gene cluster polymorphisms and other aspects of BPH development (data not shown).

\section{DISCUSSION}

TLRs play an important role in pathogen-mediated innate immunity and chronic inflammation [13]. After the recognition of foreign antigens, TLRs activate both innate and adaptive immunity. TLR1 and TLR6 combine with TLR2 to form dimers in order to recognize pathogens and induce the production of cytokines $[13,15]$. TLR10-1-6 belongs to the TLR2 subfamily and may influence the carcinogenesis of the prostate by increasing the risk of chronic inflammation [3]. However, there have been no reports of an association between BPH and the TLR6-1-10 gene cluster. In this study, we investigated whether there is a correlation between the TLR10-1-6 gene cluster and development of BPH. This is the first study to analyze the genetic correlation between TLR10-TLR1-TLR6 gene cluster promoter SNPs and the development of BPH in a Korean population.

We analyzed four TLR10-1-6 gene cluster SNPs (TLR10, rs 10004195 [-89T/A, promoter]; TLR1, rs5743557 [-459C/T, promoter]; and TLR6, rs1039560 [-344A/G, promoter] and rs1039559 [-436T/C, promoter]) in $\mathrm{BPH}$ patients and control subjects. We also investigated the association between four promoter SNPs and aspects of BPH development (prostate volumes and PSA levels). However, we did not find any association between TLR10-1-6 gene cluster SNPs and development of BPH. 
Several researchers investigated the genetic association between TLR10-1-6 gene cluster SNPs and several diseases, such as immunoglobulin A nephropathy (IgAN), urothelial bladder cancer, thyroid cancer, and prostate cancer [2,16-19]. Park et al. [17] investigated the relationship of TLR10 gene polymorphisms (rs11096957 [Asn241His], rs11096955 [Ile369Leu] and rs4129009 [Ile775Val]) with IgAN in Korean children and showed association with susceptibility to IgAN. Wurfel et al. [20] revealed that hypermorphic genetic variations in TLR1 are associated with an increased susceptibility to organ dysfunction, death, and gram-positive infection in sepsis.

The genetic variants of the TLR10-1-6 gene cluster in prostate cancer has been investigated in a Swedish case-control population and the Health Professional Follow-up Study [21]. Eleven SNPs in this gene cluster were associated with a statistically significantly increased risk of prostate cancer. Stevens et al. [19] also demonstrated that two SNPs in TLR10 (I369L [rs11096955] and N241H [rs11096957]) and four SNPs in TLR1 (N248S [rs4833095], S26L [rs5743596], rs5743595, and rs5743551) were associated with a significant reduction of $29 \%-38 \%$ in the risk of prostate cancer. In contrast, Chen et al. [13] reported that inherited sequence variants of the innate immune TLR101-6 gene cluster are not significantly associated with the risk of prostate cancer. The TLR pathway would influence the risk of prostate cancer through some inflammatory pathway, and exposure to the presumed etiologic infectious agent could vary among the three studies.

In conclusion, we did not find any correlations between the four promoter TLR10-1-6 gene cluster SNPs and the development of BPH. These results indicate that the TLR10-1-6 gene cluster may be not associated with the development of $\mathrm{BPH}$ in the Korean population.

\section{CONFLICT OF INTEREST}

No potential conflict of interest relevant to this article was reported.

\section{ACKNOWLEDGMENTS}

This work was funded by the Cooperative Research Program for Agriculture Science \& Technology Development (Project No. PJ009558), Rural Development Administration, Republic of Korea.

\section{REFERENCES}

1. Pellegrini A, Guinazu N, Giordanengo L, Cano RC, Gea S. The role of Toll-like receptors and adaptive immunity in the development of protective or pathological immune response triggered by the Trypanosoma cruzi protozoan. Future Microbiol 2011;6:1521-33.

2. Kim SK, Park HJ, Hong IK, Chung JH, Eun YG. A missense polymorphism (rs11466653, Met326Thr) of toll-like receptor 10 (TLR10) is associated with tumor size of papillary thyroid carcinoma in the Korean population. Endocrine 2013;43:161-9.

3. Takeda K, Kaisho T, Akira S. Toll-like receptors. Annu Rev Immunol 2003;21:335-76.

4. Takeuchi O, Kawai T, Sanjo H, Copeland NG, Gilbert DJ, Jenkins NA, et al. TLR6: a novel member of an expanding toll-like receptor family. Gene 1999;231:59-65.

5. Li L. Regulation of innate immunity signaling and its connection with human diseases. Curr Drug Targets Inflamm Allergy 2004;3: 81-6.

6. Hasan U, Chaffois C, Gaillard C, Saulnier V, Merck E, Tancredi S, et al. Human TLR10 is a functional receptor, expressed by B cells and plasmacytoid dendritic cells, which activates gene transcription through MyD88. J Immunol 2005;174:2942-50.

7. Wei XS, Wei CD, Tong YQ, Zhu CL, Zhang PA. Single nucleotide polymorphisms of toll-like receptor 7 and toll-like receptor 9 in hepatitis $\mathrm{C}$ virus infection patients from central china. Yonsei Med J 2014;55:428-34.

8. Yin YW, Sun QQ, Hu AM, Liu HL, Wang Q, Zhang BB. Toll-like receptor 4 gene Asp299Gly polymorphism in myocardial infarction: a meta-analysis of 15,148 subjects. Hum Immunol 2014;75: 163-9.

9. Kramer G, Mitteregger D, Marberger M. Is benign prostatic hyperplasia (BPH) an immune inflammatory disease? Eur Urol 2007;51: 1202-16.

10. Konig JE, Senge T, Allhoff EP, Konig W. Analysis of the inflammatory network in benign prostate hyperplasia and prostate cancer. Prostate 2004;58:121-9.

11. Kaplan SA. Analysis of the inflammatory network in benign prostate hyperplasia and prostate cancer. J Urol 2005;173:161.

12. Gatti G, Quintar AA, Andreani V, Nicola JP, Maldonado CA, Masini-Repiso AM, et al. Expression of Toll-like receptor 4 in the prostate gland and its association with the severity of prostate cancer. Prostate 2009;69:1387-97.

13. Chen YC, Giovannucci E, Kraft P, Lazarus R, Hunter DJ. Association between Toll-like receptor gene cluster (TLR6, TLR1, and TLR10) and prostate cancer. Cancer Epidemiol Biomarkers Prev 2007;16: 
1982-9.

14. Gabriel SB, Schaffner SF, Nguyen H, Moore JM, Roy J, Blumenstiel $\mathrm{B}$, et al. The structure of haplotype blocks in the human genome. Science 2002;296:2225-9.

15. Janssens S, Beyaert R. Role of Toll-like receptors in pathogen recognition. Clin Microbiol Rev 2003;16:637-46.

16. Guirado M, Gil H, Saenz-Lopez P, Reinboth J, Garrido F, Cozar JM, et al. Association between C13ORF31, NOD2, RIPK2 and TLR10 polymorphisms and urothelial bladder cancer. Hum Immunol 2012;73:668-72.

17. Park HJ, Hahn WH, Suh JS, Kim MJ, Kang SW, Lee JS, et al. Association between toll-like receptor 10 (TLR10) gene polymorphisms and childhood IgA nephropathy. Eur J Pediatr 2011;170:503-9.

18. Lindstrom S, Hunter DJ, Gronberg H, Stattin P, Wiklund F, Xu J, et al. Sequence variants in the TLR4 and TLR6-1-10 genes and prostate cancer risk. Results based on pooled analysis from three independent studies. Cancer Epidemiol Biomarkers Prev 2010;19:873-6. 19. Stevens VL, Hsing AW, Talbot JT, Zheng SL, Sun J, Chen J, et al. Genetic variation in the toll-like receptor gene cluster (TLR10-TLR1TLR6) and prostate cancer risk. Int J Cancer 2008;123:2644-50.

20. Wurfel MM, Gordon AC, Holden TD, Radella F, Strout J, Kajikawa $\mathrm{O}$, et al. Toll-like receptor 1 polymorphisms affect innate immune responses and outcomes in sepsis. Am J Respir Crit Care Med 2008; 178:710-20.

21. Sun J, Wiklund F, Zheng SL, Chang B, Balter K, Li L, et al. Sequence variants in Toll-like receptor gene cluster (TLR6-TLR1-TLR10) and prostate cancer risk. J Natl Cancer Inst 2005;97:525-32. 